RU Традиции экспрессионизма в современной драматургии (на примере пьес П. Туррини)

Радаева Э. А.

\begin{abstract}
Аннотация. Цель исследования - представить пьесы П. Туррини («Охота на крыс», «Всё, наконец») как произведения экспрессионистского искусства. Полученные результаты: пьесы П. Туррини являются типично экспрессионистскими как на уровне проблематики, так и на уровне элементов поэтики драматургии и театра данного модернистского направления: абстрагированный сюжет, схематизм в обрисовке героев (их деиндивидуализация), непосредственное участие в действе зрителей, жанровое своеобразие социально-философских драм и драм «возвещения» и «преображения», экспрессионистская концепция мира и человека в целом. Научная новизна исследования: впервые произведения П. Туррини рассматриваются сквозь призму эстетики экспрессионизма.
\end{abstract}

\title{
EN Traditions of Expressionism in Modern Dramaturgy (by the Example of P. Turrini's Plays)
}

\section{Radaeva E. A.}

\begin{abstract}
Finally, the End") as works of expressionist art. The research findings are as follows: P. Turrini's plays are typically expressionist both at the level of problems and at the level of the elements of drama and theatre poetics characteristic of this modernist movement: abstracted plot, oversimplified portrayal of characters (their deindividualisation), direct involvement of the audience in the action, genre originality of socio-philosophical dramas and dramas of "proclamation" and "transfiguration", expressionist concept of the world and a man as a whole. The study is novel in that it is the first to consider P. Turrini's works through the lens of expressionist aesthetics.
\end{abstract}

\section{Введение}

Актуальность исследования. В российском литературоведении крайне мало внимания уделено творчеству весьма популярного и одного из самых эпатажных современных драматургов П. Туррини, пьесы которого ставятся на подмостках как западного, так и российского театра. Известно, что на сегодняшний день искусство, особенно австрийское, претерпевает сильное влияние традиций экспрессионизма, поэтому актуальным становится рассмотрение конкретных проявлений такой рецепции. Исходя из цели исследования, основными задачами являются: обнаружить соответствия проблематики пьес П. Туррини экспрессионистской концепции взаимоотношений человека и мира; установить рецепцию художественного метода «классических» экспрессионистов в драматургии современного автора; выделить роль зрителей; проанализировать жанровое своеобразие экспрессионистского театра в пьесах «Охота на крыс», «Всё, наконец».

В качестве методов исследования выбран системно-культурологический подход, в соответствии с которым культура понимается как открытая система и предполагает интеграцию исследовательского материала из различных областей знания; проведен целостный анализ текстов пьес с элементами компаративистики.

Теоретической базой в данном случае послужили как ранние отечественные монументальные исследования экспрессионизма в литературе (Л. Копелев [6], Г. Недошивин [10]), так и более поздние работы (Ю. Борев [1], О. Мартынова [8; 9], Г. Макарова [7]).

Практическая значимость: полученные результаты могут найти применение в театроведении, в изучении и преподавании истории зарубежной литературы, мировой художественной культуры.

В российском литературоведении, в направлении современной немецкоязычной литературы и австристики, крайне мало уделено внимания современному австрийскому писателю и драматургу Петеру Туррини (род. в 1944 г.), тогда как спектакли по его пьесам (“Rozznjogd” («Охота на крыс», 1971), “Alpenglühen” 
(«Альпийское сияние», 1993), “Endlich Schluss” («Всё, наконец», 1997)) ставятся в наших театрах от СанктПетербурга до Омска. Кроме того, несмотря на популярность теории возрождения экспрессионизма, практически нет работ, где рассматривалось бы его влияние на поэтику творчества П. Туррини, а такого рода рецепция, на наш взгляд, очевидна. Представляется необходимым восполнить этот пробел и внести тем самым лепту в изучение и преподавание истории зарубежной литературы в гуманитарных вузах, а также в область современного театроведения.

В отечественном литературоведении еще в середине прошлого века было отмечено обострение научного интереса к экспрессионизму как художественному направлению, якобы зародившемуся и быстро исчерпавшему себя в 20-х годах [10]. Изучение одного из самых влиятельных модернистских течений происходило сначала в марксистском ключе - с целью использования исследований данного феномена в идеологической борьбе [16, с. 6], затем - более комплексно: в 2008 г. вышел «Энциклопедический словарь экспрессионизма» под редакцией П. М. Топера [17], где рассматривалось «новое прочтение» данного направления в искусстве. Творчество же П. Туррини упоминается вскользь, в ряду его современников, и чаще - сквозь призму проблем, связанных с разрушением и формированием национальной идентичности, пережитыми австрийцами в XX веке [3], переосмысления наследия Второй мировой войны в австрийской литературе конца XX века [5] в рамках поэтики “Schock Theater”. В зарубежной критике основное внимание обращено на сами спектакли по пьесам вышеназванного драматурга, режиссерское их видение и игру актеров [19; 20]. Немецкие театральные критики отмечают, что П. Туррини «удалось создать чудо камерной пьесы», что само по себе «драгоценность среди новинок» [20]. Итак, пьесы современного и весьма популярного австрийского драматурга ранее детально не изучались, более того, в наши дни много говорится об экспрессионистских мотивах в современной литературе в целом, однако существует мало работ с анализом конкретных проявлений этих мотивов у того или иного автора в тех или иных произведениях.

\section{Соответствие проблематики пьес экспрессионистской концепции взаимоотношений человека и мира}

Начнем с того, что по своей общей тональности драмы П. Туррини полностью отвечают всем (даже разнородным!) определениям экспрессионизма, приведенным Ю. Боревым [2]: 1) как «искусство, проникнутое нигилистическим пафосом и полное жажды сильных переживаний и стремления вырваться из мертвенной бюргерской жизни» (В. Кольшмидт); 2) как «искусство, проложившее дорогу беспредметности абстракционизма» (Ф. Марк); 3) как искусство, где «художник сам определяет форму, образ, пунктуацию и синтаксис» (Дж. Каддон); 4) как «искусство, жизненные истоки которого в “бегстве от сложности Города и Машины”, в отталкивании от рационализма, в стремлении уйти в первобытность...» (К. Эйнштейн) [1, с. 547-548].

Рассмотрим сначала реализацию заключенных в вышеприведенных определениях идей на уровне сюжетов двух выбранных нами драм. В «Охоте на крыс» главные действующие лица - Он и Она (что уже само по себе абстрактно) - будучи едва знакомыми, приезжают на городскую свалку и после бурных диалогов и взаимных обвинений в фальши и искусственности избавляются от всего наносного и преходящего: от париков, накладных ресниц и вставных зубов, содержимого сумочки и бумажника, карманов одежды и самой одежды, а затем и от самой машины, к которой мужчина был очень привязан. Всё это сделано не только с целью обрести друг друга «настоящими», но и как вызов цивилизации потребления, «бегство от сложности Города и Машины»:

«Она. Нет, ты только посмотри, какое свинство! И откуда только это все берется?

Он. Откуда берется! Из города, естественно. В один прекрасный день они засыплют свалку землей, и ты ничего не увидишь, кроме домов: одна коробка возле другой...

Она. Я только подумаю о таком, мне дурно делается. Дома, дома - и все они корнями в дерьме.

Он. Чепуха какая! Половина города стоит на отбросах...

$<\ldots>$

Он. <...> Все в нас - мусор, дерьмо, помои. Плоть, из которой ты сделана, воняет тухлыми яйцами. Ты появляешься на свет, сосешь из маминых титек молоко, и оно скисает у тебя в брюхе. Сверху в тебя заталкивают еду, а снизу выходит дерьмо... Потом ты идешь в школу, и учителя набивают тебе мозги истинами, которые сгнили уже тысячу лет назад. <...> А еще я научился в ней курить. Сегодня я выкуриваю тридцать в день. Смолой из моих легких можно заасфальтировать всю аллею Зиммерингер. Каждое воскресенье я иду в кино... Один порнографический фильм за другим входят в мою голову, словно больная кровь, понимаешь?.. А на работе всю неделю они говорят только о бабах и о постели. К вечеру внутри смердит, как в борделе... Все в нас - дерьмо, мусор, помои... Стоит только кому-нибудь открыть рот, и кажется, что сейчас утонешь в сточной канаве!» [15].

В драме «Всё, наконец» единственный в списке действующих лиц герой, исполненный сильных переживаний, подобно самому искусству экспрессионизма (по В. Кольшмидту) «вырывается из мертвенной бюргерской жизни», как ни парадоксально, с помощью суицида: он становится глубоко отвратительным самому себе ввиду постоянной фальши, к которой должен прибегать в жажде социального успеха (которого достигает к тому времени), фальшивость и гнилостность окружающего его мира он давно уже воспринимает как нечто само собой разумеющееся.

Л. Копелев выделяет следующие общие для всей драматургии экспрессионистов черты:

«- Отказываясь от правдоподобия в построении сюжетов и в развитии отдельных образов, они утверждают открыто выраженные социально-философские... или нравственные идеи. 
- Большинству пьес присущ обнаженный схематизм коллизий, представленных нередко в фантастически условных, аллегоричных сюжетах.

- Персонажи почти лишены конкретной индивидуализации...

- Язык... чаще всего поэтически “приподнят”, напряжен, условен, далек от обиходной живой речи» [6, с. 72].

Итак, в первой из указанных пьес представлено нечто вроде апокалипсиса (то есть правдоподобие реальной жизни лишь условное). Главное место в городе - свалка. Излюбленное занятие людей - охота на крыс. Главных героев и убивают, приняв за крыс, внезапно появившиеся в финале эпизодические персонажи («первый мужчина», «второй мужчина»). Во второй из анализируемых нами пьес замкнутое пространство совершенно пустой и задрапированной в черное квартиры очень успешного журналиста, отгородившегося от «вещественного мира людей» (то есть от людей и от вещей). В первой пьесе герои бросают вызов обществу потребления, отказываясь быть его представителями и жертвами, в финале их по ошибке убивают. Ошибка, разумеется, тоже условна, так как в финале звучит ставшая банальной в XXI веке мысль: люди как крысы и крысы как люди. Человек, отказавшийся стать частью «пластиковой»/«нейлоновой» цивилизации и оказавшийся один на один с собой - «голым человеком на голой земле» - обретает себя, но перестает быть человеком в глазах других. Во второй пьесе сюжет также схематичен: герой, объявляя о своем решении свести счеты с жизнью, после того как досчитает до 1000, произносит длинный монолог о себе, стреляется, падает.

\section{Рецепция художественного метода «классических» экспрессионистов в драматургии П. Туррини}

В обеих пьесах персонажи деиндивидуализированы: в первой - Он, Она, во второй - Мужчина.

Диалоги и монолог в этих двух пьесах соответственно не лишены приподнятости, ибо речи пафосны, экспрессивны, эмоциональны, обращены будто бы в никуда.

1. «Он. Помяни, господи, их души! (После паузы.) Когда я думаю о том, что эти мерзкие животные - крысы, - возможно, переживут атомную войну, я схожу с ума от этой злости... Нас разнесет на мелкие кусочки, и наши останки будут валяться кругом, как блевотина в квартале, где торгуют молодым вином, и тысяча, миллионы, миллиарды крыс будут пожирать наши обгоревшие кости... / Дерьмо! Все в тебе искусственное. Твой мозг - раковина, в которую стекают чужие испражнения! Твое лицо - кладбище косметики. Даже волосы у тебя ненастоящие, это же конские волосы или еще чья-нибудь щетина» [15].

2. «Я перенес страшные болезни, но ни одной не удалось сразить меня, ни одна не загасила во мне искру жизни. Я прочитал книги о смертельных болезнях величайших из великих. Когда я начал кашлять подобно Кафке, то обращался в разные санатории, полагая, что у меня вот-вот начнется кровохарканье. Я обследовал свое тело в поисках узлов ницшеанской венерической болезни, я пьянствовал, подражая Хемингуэю, курил сигарету за сигаретой и надеялся, что смогу, как Пуччини, умереть от рака горла. Я желал, чтобы меня вслед за Бюхнером, уничтожил тиф, я жаждал быть насмерть покусанным собакой, как Фердинанд Раймунд, или, на худой конец, погибнуть, как Албан Берг, от укуса насекомого. Свою семью, своих друзей я ставил перед фактом угрожающей моей жизни опасной болезни, а замечая падение их интереса к моему состоянию, я по секрету сообщал им о моей предстоящей смерти. Я рассылал им всем копии рентгеновских снимков, на которых были видны затемнения. Однако чем настойчивее демонстрировал я им приметы своей скорой гибели, тем безразличнее становился я для них и тем равнодушнее начинал сам относиться к собственным болезням. И тогда я решил покончить с собой» [13].

И в «Охоте на крыс», и в пьесе «Всё, наконец» герои, как, например, в драмах экспрессиониста начала века Рейнгардта Зорге, - «искатели истинного самопознания», утверждающие «естественную человечность».

\section{Роль зрителей в драмах П. Туррини}

Еще одно неотъемлемое свойство поэтики экспрессионистской драмы и, соответственно, театра - роль зрителей. По словам Г. Макаровой, «театр немецкого экспрессионизма выдвинул новое понимание роли зрителей, которые уже в ходе спектакля должны были стать членами общего “духовного братства”» [7, с. 550]. Действительно, в пьесах П. Туррини зрительный зал - непосредственный участник действа, а не лишь созерцатель. В «Охоте на крыс» герои периодически стреляют в зал или показывают на него рукой, будто бы провозглашая, что крысы - все мы, человечество:

«Она (показывает рукой в зрительный зал, кричит). Там крыса! Мама! Там крыса!

Он (спокойно шарит на заднем сиденье и достает ружье; встает, целится в публику, стреляет; потом счастливым голосом). Этой - хана. Аминь.

Она (испуганно). Пожалуйста, стреляй, там еще одна...

Он (снова целится в публику, стреляет)» [15].

В пьесе «Всё, наконец» Мужчина, приближаясь к цифре, после которой должен раздаться выстрел, так же обращается к залу (это просто крик, подобно тому, что запечатлен на картине Э. Мунка - без надежды, что его услышат, без надежды на сострадание):

«800

(Становится перед воображаемой четвертой стеной и кричит в публику.)

900» [13]. 


\section{Жанровое своеобразие пьес}

Последний вопрос, который представляется необходимым затронуть в данном исследовании, - проблема жанра указанных драматургических произведений. Л. Копелев в экспрессионистском театре выделяет три группы драм: отвлеченно-философские (мистические), «социально-философские по сути, но по сюжетам чаще всего исторические или условно-аллегорические и символические», «социально-политические и социально-философские, непосредственно злободневные критические или революционные драмы» [6, с. 49-50].

Исходя из вышеизложенной проблематики исследуемых произведений, можем причислить их к социальнофилософским.

О. Мартынова выделяет такие разновидности экспрессионистской драмы, как «драма возвещения» [8] и «драма преображения» [9]. В первой «сценическое пространство уподоблялось трибуне на площади или кафедре проповедника» [8, с. 204]; во второй «характер и структура... определяются актом “преображения” героя, трактуемым с различных... философских позиций» [9, с. 205]. Очевидно, что пьесу «Всё, наконец» можно трактовать как драму возвещения, где только и есть трибуна и герой, и отчасти - как драму преображения (герой своей смертью пресекает свои многочисленные лицедейства в ненавистном ему социуме); «Охоту на крыс» - как драму преображения: герои погибают, перед тем намеренно очистив себя от «скверны» общественных условностей.

\section{Заключение}

Как уже было сказано ранее, в проанализированных нами исследованиях, посвященных творчеству П. Туррини и его взаимоотношениям с экспрессионистской эстетикой, конкретных материалов найдено не было, хотя о нем как о драматурге говорится больше, нежели как о поэте и прозаике [18]. В интернет-пространстве чаще находим отзывы читателей о пьесах австрийского драматурга, подчеркивающие актуальность затрагиваемых им проблем на сегодняшний день [14], отзывы зрителей на спектакли по творчеству П. Туррини, указывающие на глубину затрагиваемых автором психологических проблем, главная из которых - одиночество человека [4]. Однако среди кратких безымянных аннотаций на сайте одной из российских библиотек находим следующее резюме: “Охота на крыс” (1971) - самая известная пьеса Петера Туррини, посвященная проблемам молодежи. Предельная жестокость в ней соединена с сочувствием и любовью к героям, неожиданность ситуации - с великолепным диалогом, элементы театра Брехта и театра абсурда сплетаются с приемами немецкого народного театра» [11]. Подобный вердикт не противоречит нашей теории: ранний Брехт был экспрессионистом, хоть и критиковал впоследствии данное направление, драма абсурда является «смежным» с экспрессионизмом направлением, однако бессвязных монологов и диалогов, характерных для нее, у Туррини мы не находим. На одном из сайтов театральной жизни Архангельска встречаем и такое нетривиальное видение драматургии австрийского художника: «По мнению одного из провинциальных режиссеров, спектакль “Охота на крыс” поставлен в жанре “кинетико-утопической трагедии” - так определил жанр спектакля его режиссер Роман Абрамовский. Мастер курса - Роман Абрамовский, руководитель экспериментального любительского театра “Жизнь” [12]. Но всё это, по большому счету, лишь частные и научно не обоснованные мнения.

Выводы. Настоящее исследование позволяет заключить, что поэтика и проблематика пьес П. Туррини «Охота на крыс» и «Всё, наконец» почти полностью отвечают экспрессионистскому мировидению и соответствующему художественному методу. Сюжет абстрагирован, герои обрисованы схематично (они деиндивидуализированы), зрители принимают непосредственное участие в театральном действе, по жанру пьесы отвечают эстетике социально-философских драм и драм «возвещения» и «преображения», концепция мира и человека в целом достаточно пессимистична.

Перспективы дальнейшего исследования. Актуальным представляется дальнейшее исследование как творчества одного из самых эпатажных современных драматургов, так и проблем влияния традиций экспрессионизма на современную литературу и театр.

\section{Список источников}

1. Борев Ю. Б. Экспрессионизм // Бореев Ю. Б. Эстетика. Теория литературы: энциклопедический словарь терминов. М.: Астрель; АСТ, 2003. С. 547-548.

2. Борев Ю. Б. Эстетика. Теория литературы: энциклопедический словарь терминов. М.: Астрель; АСТ, 2003. 575 с.

3. Ефименко Е. Немецкоязычная литература Австрии, или Своеобразие австрийской прозы второй половины XX века // Филологические науки. Вопросы теории и практики. 2013. № 1 (19). С. 80-82.

4. Кашникова Л. Попробуем возлюбить Крысу, живущую в нас... [Электронный ресурс]. URL: https://web.archive.org/ web/20150610131934/http://home.uic.tula.ru/press/p_ohota.htm\#8 (дата обращения: 18.02.2021).

5. Ковтун Н. В., Ларина М. В. Переосмысление наследия Второй мировой войны в австрийской литературе конца XX века // Гуманитарный вектор. 2020. Т. 15. № 1. С. 49-59.

6. Копелев Л. Драматургия немецкого экспрессионизма // Экспрессионизм: сборник статей / под ред. Г. Недошивина. М.: Наука, 1966. С. 36-83. 
7. Макарова Г. Театр и экспрессионизм // Словарь экспрессионизма / под ред. П. М. Топера. М.: ИМЛИ РАН, 2008. C. 547-552.

8. Мартынова О. Драма возвещения // Энциклопедический словарь экспрессионизма / под ред. П. М. Топера. М.: ИМЛИ РАН, 2008. С. 204-205.

9. Мартынова О. Драма преображения // Энциклопедический словарь экспрессионизма / под ред. П. М. Топера. М.: ИМЛИ РАН, 2008. С. 205-206.

10. Недошивин Г. Проблема экспрессионизма // Экспрессионизм: сборник статей / под ред. Г. Недошивина. М.: Наука, 1966. С. 8-35.

11. Охота на крыс [Электронный ресурс]. URL: https://www.aonb.ru/event/845-ohota-na-krys.html (дата обращения: 18.02.2021).

12. Спектакль по пьесе Петера Туррини «Охота на крыс» [Электронный ресурс]. URL: https://kuda29.ru/ arh/e/20422-ohota_na_krys (дата обращения: 18.02.2021).

13. Туррини П. Всё, наконец: монолог [Электронный ресурс] / пер. с нем. Л. Бухова. URL: http://lib.ru/PXESY/ TURRINI/turrini.txt (дата обращения: 18.02.2020).

14. Туррини П. Охота на крыс [Электронный ресурс] / пер. М. Заславской. URL: https://www.livelib.ru/ work/1000747283/stories-ohota-na-krys-peter-turrini (дата обращения: 18.02.2020).

15. Туррини П. Охота на крыс: пьеса в одном действии [Электронный ресурс]. URL: https://www.litmir.me/ $\mathrm{br} / ? \mathrm{~b}=593455$ (дата обращения: 18.02.2021).

16. Экспрессионизм: сборник статей / под ред. Г. Недошивина. М.: Наука, 1966. 196 с.

17. Энциклопедический словарь экспрессионизма / под ред. П. М. Топера. М.: ИМЛИ РАН, 2008. 736 с.

18. Peter Turrini [Электронный ресурс] // Archivederzeitgenossen. URL: https://www.archivderzeitgenossen.at/ archivbestand/vorlass-peter-turrini/ (дата обращения: 18.02.2020).

19. Peter Turrini. Endlich Schluß [Электронный ресурс]. URL: https://www.josefstadt.org/programm/stuecke/archiv19981999-20182019/stueck/endlich-schluss.html (дата обращения: 05.02.2020).

20. Peter Turrini. Gemeinsamist Alzheimer schooner: Uraufführung [Электронный ресурc]. URL: www.josefstadt.org/ programm/stuecke/stueck/gemeinsam-ist-alzheimer-schoener.html (дата обращения: 17.02.2020).

\section{Информация об авторах | Author information}

RU Радаева Элла Александровна ${ }^{1}$, к. филол. н.

${ }^{1}$ Самарский государственный социально-педагогический университет

EN Radaeva Ella Alexandrovna ${ }^{1}, \mathrm{PhD}$

${ }^{1}$ Samara State Social and Pedagogical University

${ }^{1}$ ellrad@yandex.ru

\section{Информация о статье | About this article}

Дата поступления рукописи (received): 13.03.2021; опубликовано (published): 30.04.2021.

Ключевые слова (keywords): Петер Туррини; экспрессионизм; «Охота на крыс»; «Всё, наконец»; Peter Turrini; expressionism; "Rat Hunt"; "Finally, the End". 